STUDI

FRANCESI

\section{Studi Francesi}

Rivista quadrimestrale fondata da Franco Simone

194 (LXV | II) | 2021

Baudelaire et son cénacle

\title{
MATTHEW D'AURIA, The Shaping of French National Identity, Narrating the Nation's Past, 1715-1830
}

\section{Paola Cattani}

\section{OpenEdition}

\section{Journals}

\section{Édition électronique}

URL : https://journals.openedition.org/studifrancesi/45139

DOI : 10.4000/studifrancesi.45139

ISSN : 2427-5856

\section{Éditeur}

Rosenberg \& Sellier

\section{Édition imprimée}

Date de publication : 1 août 2021

Pagination : 376-377

ISSN : 0039-2944

\section{Référence électronique}

Paola Cattani, « MATTHEW d'AURIA, The Shaping of French National Identity, Narrating the Nation's Past,

1715-1830 », Studi Francesi [En ligne], 194 (LXV | II) | 2021, mis en ligne le 01 septembre 2021, consulté le 15 octobre 2022. URL : http://journals.openedition.org/studifrancesi/45139; DOI : https://doi.org/ 10.4000/studifrancesi.45139

Ce document a été généré automatiquement le 15 octobre 2022

\section{(c) $($ ) $(9)$}

Creative Commons - Attribution - Pas d'Utilisation Commerciale - Pas de Modification 4.0 International - CC BY-NC-ND 4.0

https://creativecommons.org/licenses/by-nc-nd/4.0/ 


\title{
MATTHEW D'AURIA, The Shaping of French National Identity, Narrating the Nation's Past, 1715-1830
}

\author{
Paola Cattani
}

\section{RÉFÉRENCE}

MATTHEW D'AURIA, The Shaping of French National Identity, Narrating the Nation's Past, 1715-1830, Cambridge, Cambridge University Press, 2020, 473 pp.

1 Un frequente punto di partenza delle trattazioni sull'identità nazionale della Francia (e non solo) è il celebre testo di Renan del 1882, Qu'est-ce qu'une nation?, che propone una definizione cosiddetta «volontaristica» della nazione, come entità definita non dalla razza, dalla lingua o dalla religione, bensì dal desiderio di vivere assieme, dalla volontà comune di «continuare a far valere l'eredità ricevuta». Nello studio di Matthew D'Auria, il testo di Renan figura invece quale punto di arrivo: sia per quanto riguarda lo sviluppo argomentativo del volume, poiché a Renan è dedicato il capitolo conclusivo intitolato appunto «About Renan», sia per quanto concerne l'arco cronologico preso in esame, poiché il volume studia precisamente ciò che ha preceduto la definizione renaniana, ovvero l'ampio dibattito che si articola tra XvIII e inizio del xIx secolo sull'identità e le origini della nazione francese. The Shaping of French National Identity getta così luce su un capitolo di storia intellettuale finora mai indagato con tale completezza, quello delle battaglie tra visioni concorrenti dell'identità nazionale che convivono nel corso di un «lungo» XVIII secolo; fulcri del dibattito sono in particolare la valutazione dei contributi rispettivi di Galli, Romani e Franchi nella storia francese, e la riflessione sul ruolo del re, dei nobili, e del resto della popolazione nella creazione della nazione. Nello scandagliare diatribe e visioni contrastanti, il volume disvela possibili immagini alternative a quella fissatasi nella seconda metà dell'Ottocento, e illumina i sentieri e le ragioni dell'affermazione della narrativa egemone. Si tratta di un approccio alla 
questione dell'identità nazionale capace di essere innovativo pur all'interno di una bibliografia vasta e prestigiosa: focalizzandosi sull'idea di «narrativa nazionale», questo approccio ripara ad alcuni degli assunti impliciti agli approcci cosiddetti «modernista», quello dei celebri lavori di Eric Hobsbawn e Benedict Anderson, ed «etno-simbolico», che fa capo in particolare ad Anthony D. Smith, non senza introdurre per altri versi una problematizzazione nei lavori sulle «memorie» nazionali come luoghi di congiunzione di passato e presente, ovvero di storia, rappresentazioni e proiezioni.

Il libro è organizzato in tre parti, dedicate ad altrettante nozioni decisive per il discorso sull'identità nazionale francese: razza, mœurs e classe, analizzate nelle loro implicazioni storiche e teoriche attraverso alcuni testi fondanti e i riverberi da essi suscitati nel dibattito contemporaneo. Il primo capitolo affronta la nozione di «razza» attraverso gli scritti in particolare di Boulainvilliers, ma anche di Saint-Simon, del Père Daniel e dell'abbé Dubos; il secondo capitolo è dedicato alla nozione di mœurs, indagata attraverso anzitutto l'opera di Montesquieu, ma anche La Bruyère, Voltaire, Mme de Staël, Mably; il terzo capitolo affronta la nozione di «classe» specialmente attraverso Augustin Thierry, ma anche Siéyès, Guizot, Mignet. Un ricco percorso di storia concettuale viene così dipanato, attraverso quelli che sono concetti che non smetteranno di essere problematici e cruciali non solo per tutto l'Ottocento, ma anche per buona parte del Novecento. Studiando opere che sono al tempo stesso filosofiche, storiche e letterarie, il volume risulta importante non solo per chi si interessi alla storia francese, ma anche per chi studi la produzione letteraria di XvIII e xIx secolo.

Numerose sono le questioni che il volume intercetta e sulle quali fornisce illuminanti puntualizzazioni. Tra le altre, le diverse idee di libertà che si trovano via via al cuore del dibattito sull'identità nazionale (si pensi in particolare alla supposta libertà dei Franchi); il ruolo di volta in volta attribuito a Roma e all'eredità latina nel passato della nazione; la lunga gestazione intellettuale della nozione di mœurs, debitrice dei discorsi sugli stereotipi nazionali e delle spiegazioni «climatiche» dei caratteri nazionali; le successive ridefinizioni del ruolo politico di nobiltà e borghesia, operate tanto attraverso battaglie sullo status legale, quanto attraverso il dibattito concernente le qualità morali; infine e soprattutto, lo stretto legame ravvisabile tra la nozione di mours e un tipo di liberalismo francese, di impronta repubblicana, che mette al centro la società, e quindi la partecipazione e l'educazione. Attraverso il suo documentato percorso, il volume ci racconta dunque di come il passato è stato di volta in volta ricordato e/o dimenticato per modellare il presente e il futuro della nazione. 